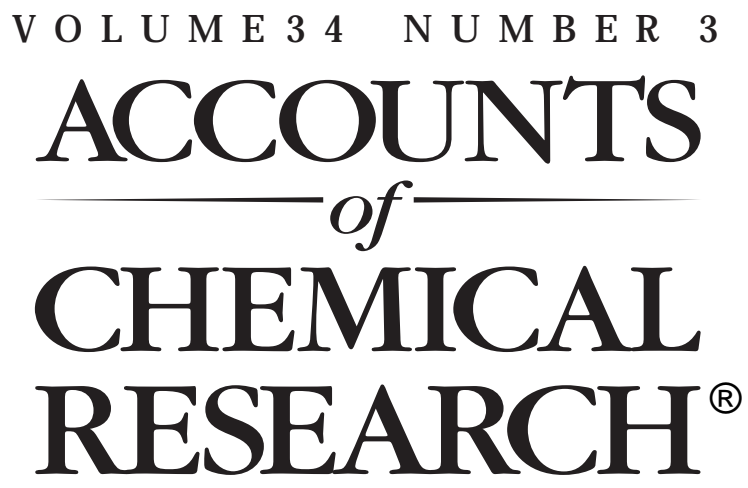

MARCH 2001

\title{
Dendrimer-Encapsulated Metal Nanoparticles: Synthesis, Characterization, and Applications to Catalysis
}

\begin{abstract}
RICHARD M. CROOKS,* MINGQI ZHAO, LI SUN, VICTOR CHECHIK, AND LEE K. YEUNG Department of Chemistry, Texas A\&M University, P.O. Box 30012, College Station, Texas 77842-3012

Received J une 16, 2000

\section{ABSTRACT}

This Account reports the synthesis and characterization of dendrimer-encapsulated metal nanoparticles and their applications to catalysis. These materials are prepared by sequestering metal ions within dendrimers followed by chemical reduction to yield the corresponding zerovalent metal nanoparticle. The size of such particles depends on the number of metal ions initially loaded into the dendrimer. Intradendrimer hydrogenation and carbon-carbon coupling reactions in water, organic solvents, biphasic fluorous/ organic solvents, and supercritical $\mathrm{CO}_{2}$ are also described.
\end{abstract}

\section{Introduction}

This Account reports the synthesis and characterization of dendrimer-encapsulated metal nanoparticles and their applications to catalysis (Scheme 1). In this approach, discrete, well-defined polymers known as dendrimers ${ }^{1,2}$ are used as templates to control the size, stability, and

Richard M. Crooks received his Bachelor of Science degree in chemistry from the University of Illinois (Urbana, IL) and his doctoral degree in electrochemistry from the University of Texas (Austin, TX) in 1987. He is currently Professor of Chemistry and Director of the Center for Integrated M icrochemical Systems at Texas A\&M University. His research interests include chemical sensors and interfacial design, catalysis, electrochemistry, nanomaterials, and applications of microfluidic devices.

M ingqi Zhao received his Bachelor of Science degree in corrosion and protection from Hewing University of Technology (Hingham, China), his M aster of Science degree in applied chemistry from Nanjing University of Chemical Technology (Naming, China), and his doctoral degree in analytical and materials chemistry from Texas A\&M University. At present he is employed as a senior scientist at ACLARA BioSciences, Inc. (M ountain View, CA). His research interests include microfluidic devices, polymers, surface chemistry, and on-chip electrochemistry. solubility of nanoparticles ranging in diameter from less than $1 \mathrm{~nm}$ up to 4 or $5 \mathrm{~nm}$. Dendrimers are particularly well-suited for hosting metal nanoparticles for the following reasons: (1) the dendrimer templates themselves are of fairly uniform composition and structure, and therefore they yield well-defined nanoparticle replicas; ${ }^{3-7}$ (2) the nanoparticles are stabilized by encapsulation within the dendrimer, and therefore they do not agglomerate; ${ }^{3-9}$ (3) the encapsulated nanoparticles are confined primarily by steric effects, and therefore a substantial fraction of their surface is unpassivated and available to participate in catalytic reactions; $4,5,7-10$ (4) the dendrimer branches can be used as selective gates to control access of small molecules (substrates) to the encapsulated (catalytic) nanoparticles; ${ }^{4,11}$ (5) the terminal groups on the dendrimer periphery can be tailored to control solubility of the hybrid nanocomposite and used as handles for facilitating linking to surfaces and other polymers., ${ }^{5,7-15}$ As will be discussed later, these five attributes take full advantage of the unique structural and chemical properties of dendrimers. Indeed, dendrimer/nanoparticle composites represent an unusual

\footnotetext{
* To whom correspondence should be directed. Voice: 979-845-5629.
} Fax: 979-845-1399. E-mail: crooks@tamu.edu.

Li Sun received his undergraduate education from Beijing University (1979-1983) and a Ph.D. degree in chemistry from Northwestern Univeristy (1990). At present he is a research associate at Texas $A \& M$ University. His research interests include catalysis based on dendrimers and fluidic transport through nanoporous media.

Victor Chechik received his Dipl. Chem. from Leningrad State University in Russia and his Cand. Sci. (Russian equivalent of Ph.D.) from St.-Petersburg Institute of Technology (Russia) in 1994. He is currently an Astra-Zeneca Lecturer in Physical Organic Chemistry at the University of York (UK). His research interests include nanomaterials, surpamolecular assemblies, organic molecular films, and reactivity at interfaces.

Lee K. Yeung was born in New York, NY, in 1971. He obtained a Bachelor of Arts degree in chemistry from Hendrix College (Conway, AR) with distinction in 1993. Under the supervision of Prof. Dwight Sweigart at Brown University (Providence, RI), he completed his Ph.D. thesis in 1997, which centered on the synthesis and electrochemical characterization of bimetallic organometallic complexes. In the same year, he began working as a postdoctoral research associate in Prof. Catherine M urphy's laboratory at the University of South Carolina, and in 1999, he continued his postdoctoral training at Texas A\&M University with Prof. Richard M. Crooks. He is currently a Research Scientist at Dow Chemical (Freeport, TX). His research interests include organometallic synthesis, nanomaterials, molecular electronics, self-assembly strategies, and environmentally responsive materials. 
Scheme 1

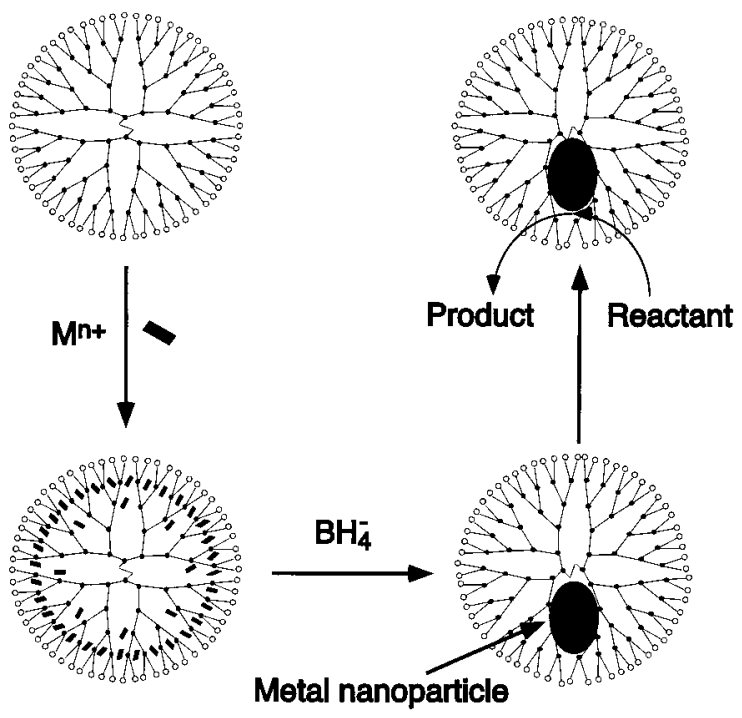

case of the template and replica working in concert to exhibit functions that exceed those of the individual components. That is, in the studies reported here the dendritic templates play a role well beyond that of a simple casting mold.

Our new findings build on numerous previous templatebased strategies for preparing metal nanoparticles. ${ }^{16-19}$ For example, polymers (especially diblock copolymers) with metal-ion affinities can be used to sequester metal ions into localized domains that can subsequently be converted into metal nanostructures. ${ }^{16} \mathrm{~A}$ wide range of metal particles have been formed within such polymer templates including $\mathrm{Cu}, \mathrm{Ag}, \mathrm{Au}, \mathrm{Pt}, \mathrm{Pd}$, and $\mathrm{Rh}$. The polymer template usually serves to both control particle size and passivate the surface of the nanoparticles against agglomeration. Many different types of insulating nanoparticles have also been prepared using various kinds of templates.

Monolithic ceramic and polymeric templates have also been used for preparing nanomaterials. For example, the well-defined pores in alumina or polymeric filtration membranes can be used to define the geometrical and chemical properties of metal, semiconductor, and polymeric nanomaterials. ${ }^{20-22}$ In many cases the template can be removed chemically or thermally, leaving behind the naked nanomaterial. The obvious advantage of this technique is that highly monodisperse particles with a variety of shapes, sizes, and chemical compositions can be prepared..$^{20}$

Finally, it is important to mention that dendrimers have been previously used to stabilize and control the growth of nanoparticles by forming interdendrimer complexes (in contrast to the intradendrimer composites that are the focus of this Account). Using this approach, Murphy and co-workers prepared agglomerates of CdS and dendrimers. ${ }^{23}$ We have prepared related materials consisting of $\mathrm{Au}$ and dendrimers, ${ }^{24}$ and Esumi and co-workers have prepared $\mathrm{Pt}, \mathrm{Au}$, and Ag nanoparticles stabilized by dendrimers sorbed to their exterior. 25,26
Scheme 2<smiles>NCC(=O)NCCN(CCNC(=O)CN)CCNC(=O)CCN(CCN(CCNC(=O)CN)CCNC(=O)CN)CCN(CCNC(=O)CCN(CCNC(=O)CN)CCNC(=O)CN)CCNC(=O)CN(CCNC(=O)CN)CCNC(=O)CN</smiles>

G1 PAMAM Dendrimer

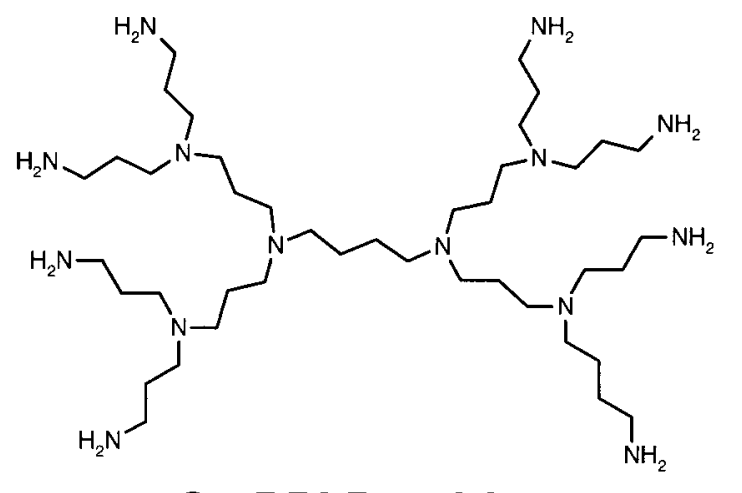

G1 PPI Dendrimer (not to scale)

Chemical and Structural Properties of Dendrimers. The chemical structures of the two families of dendrimers used in the studies reported here, poly(amidoamine) (PAMAM) and poly(propylene imine) (PPI) dendrimers, are shown in Scheme 2 . The number of functional groups on the dendrimer surface increases exponentially as a function of generation, and the resulting steric crowding on the periphery causes geometrical changes. For example, the G1 PAMAM dendrimer shown in Scheme 2 has an expanded or "open" configuration, while it is productive to think of G4 as having a porous, globular structure and G8 as a spheroid with a somewhat impenetrable surface. For a particular generation the PPI dendrimers are substantially smaller than PAMAM dendrimers $(2.8 \mathrm{~nm}$ vs $4.5 \mathrm{~nm}$ for $\mathrm{G} 4$, respectively). ${ }^{27}$ Dendrimers that are of sufficiently high generation to have developed a threedimensional shape have interior void spaces that are large enough to accommodate nanoscopic guests of various sorts (vide infra). ${ }^{28}$

An important distinction between PPI and PAMAM dendrimers is that the former are stable at very high temperatures (the onset of weight loss for G4 PPI is 470 ${ }^{\circ} \mathrm{C}$ ), whereas PAMAM dendrimers undergo retro-Michael addition at temperatures higher than about $100{ }^{\circ} \mathrm{C} .{ }^{29}$ One final point: both PAMAM and PPI dendrimers contain a statistical distribution of defects, mainly in the form of missing branches and loops. ${ }^{2,30}$ Within the resolution of 
our measurements, however, these template imperfections do not appreciably affect nanoparticle polydispersity.

Dendrimers as Host Materials. As a consequence of their three-dimensional structure and multiple internal and external functional groups, higher generation dendrimers are able to act as hosts for a range of ions and molecules. Dendrimers retain guest molecules selectively depending on the nature of the guest, the chemical composition of the dendrimer interior and periphery, and the cavity size. The driving force for guest encapsulation within dendrimers can be based on covalent bond formation, electrostatic interactions, complexation reactions, steric confinement, various types of weaker forces (van der Waals, hydrogen bonding, etc.), and combinations thereof. Many examples of dendrimer-based host-guest chemistry have been reported. 2,28

We endeavor to trap metal ions exclusively within the interiors of dendrimers. It is possible to prevent metalion complexation to the periphery of amine-terminated dendrimers either by selective protonation of the primary amines (for PAMAM dendrimers, the surface primary amines $\left(\mathrm{pK}_{\mathrm{a}}=9.5\right)$ are more basic than the interior tertiary amines $\left.\left(\mathrm{pK}_{\mathrm{a}}=5.5\right)\right)^{3,8,30}$ or by functionalization with noncomplexing terminal groups. ${ }^{3-5}$ The latter approach eliminates the restrictive $\mathrm{pH}$ window necessitated by selective protonation. Accordingly, most of our work has focused on nth-generation hydroxyl-terminated PAMAM dendrimers $(\mathrm{Gn}-\mathrm{OH})$. Indeed, we have shown that many metal ions, including $\mathrm{Cu}^{2+}, \mathrm{Pd}^{2+}, \mathrm{Pt}^{2+}, \mathrm{Ni}^{2+}, \mathrm{Au}^{3+}$, and $\mathrm{Ru}^{3+}$, sorb into $\mathrm{Gn}-\mathrm{OH}$ interiors over a broad range of $\mathrm{pH}$ via chemical interactions with interior tertiary amines.

Intradendrimer Complexes between PAMAM Dendrimers and $\mathbf{C u}^{2+}$. The first studies of dendrimerencapsulated metal ions focused on $\mathrm{Cu}^{2+}, 3,31$ because $\mathrm{Cu}^{2+}$ complexes with PAMAM and PPI dendrimers have easily interpretable UV-vis and EPR spectra. In the absence of dendrimer (or other strong ligands) and in aqueous solutions, $\mathrm{Cu}^{2+}$ exists primarily as $\left[\mathrm{Cu}\left(\mathrm{H}_{2} \mathrm{O}\right)_{6}\right]^{2+}$, which gives rise to a broad, weak absorption band centered at $810 \mathrm{~nm}$ (spectrum 2, Figure 1a) resulting from the $\mathrm{d}-\mathrm{d}$ transition for $\mathrm{Cu}^{2+}$ in a ligand field.

In the presence of a fourth-generation hydroxylterminated PAMAM dendrimer (G4-OH), $\lambda_{\max }$ for the $\mathrm{Cu}^{2+}$ $\mathrm{d}-\mathrm{d}$ transition becomes more prominent and shifts to 605 $\mathrm{nm}$. In addition, a strong ligand-to-metal charge-transfer (LMCT) transition centered at $300 \mathrm{~nm}$ emerges. The complexation interaction between dendrimers and $\mathrm{Cu}^{2+}$ is strong: the $\mathrm{d}-\mathrm{d}$ transition band and the LMCT transition do not decrease significantly, even after dialysis against pure water for $36 \mathrm{~h}$. We quantitatively assessed the number of $\mathrm{Cu}^{2+}$ ions extracted into each dendrimer by spectrophotometric titration. UV-vis spectra for a 0.05 $\mathrm{mM}$ G4-OH solution containing different amounts of $\mathrm{Cu}^{2+}$ are given in Figure $1 \mathrm{~b}$. A summary of the titration results (Figure $1 b$, inset) indicates that the absorbance at $\lambda_{\max }$ increases with the ratio of $\left[\mathrm{Cu}^{2+}\right] /[\mathrm{G} 4-\mathrm{OH}]$. The titration endpoint is obtained by extrapolating the two linear regions of this curve, and this treatment indicates that each G4-OH dendrimer can strongly sorb up to $16 \mathrm{Cu}^{2+}$
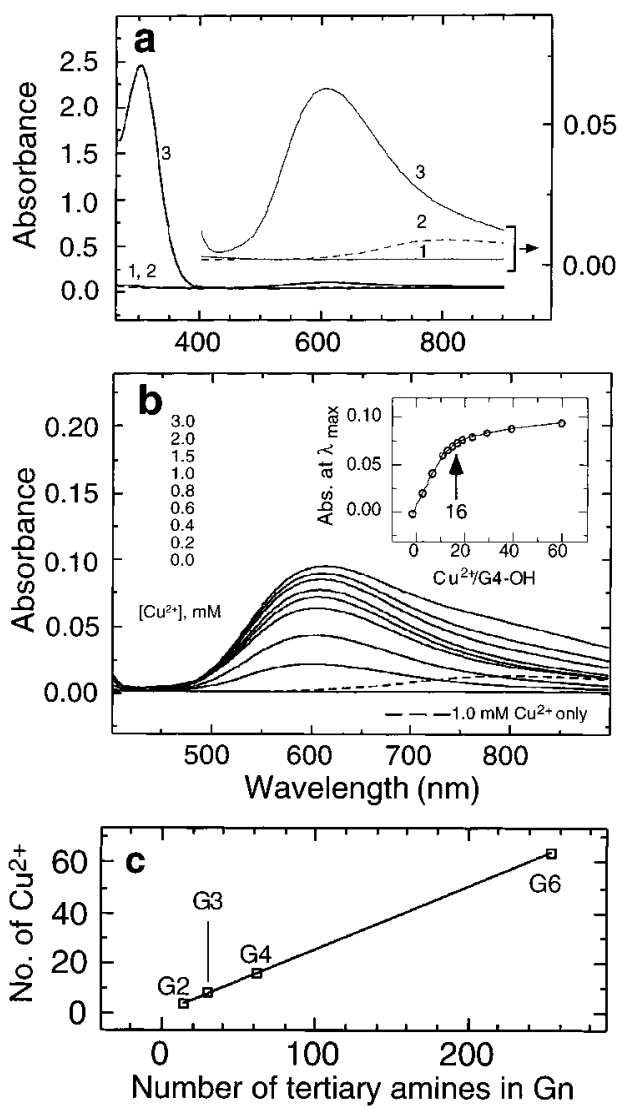

FIGURE 1. (a) Absorption spectra of $0.6 \mathrm{mM} \mathrm{CuSO}_{4}$ in the presence (spectrum 3) and absence (spectrum 2) of $0.05 \mathrm{mM} \mathrm{G4}-\mathrm{OH}$. The absorption spectrum of $0.05 \mathrm{mM} \mathrm{G4-OH}$ vs water is also shown (spectrum 1). (b) Absorption spectra as a function of the $\mathrm{Cu}^{2+} / \mathrm{G} 4-$ $\mathrm{OH}$ ratio. The inset is a spectrophotometric titration plot showing absorbance at $\lambda_{\max }$ as a function of number of $\mathrm{Cu}^{2+}$ ions per $\mathrm{G} 4$ $\mathrm{OH}$. (c) The relationship between the number of $\mathrm{Cu}^{2+}$ ions complexed within $\mathrm{Gn}-\mathrm{OH}$ and the number of tertiary amine groups within $\mathrm{Gn}$ $\mathrm{OH}$. Data were obtained in unbuffered solutions $(\mathrm{pH} \sim 7.5)$.

ions at $\mathrm{pH}>\sim 7.5 .^{32}$ We also investigated the effect of dendrimer generation on the maximum number of $\mathrm{Cu}^{2+}$ ions that can bind within dendrimers of other generations, and the endpoints of the spectrophotometric titration curves for $\mathrm{G} 2-\mathrm{OH}, \mathrm{G} 3-\mathrm{OH}$, and $\mathrm{G} 6-\mathrm{OH}$ indicate strong binding of 4,8 , and $64 \mathrm{Cu}^{2+}$ ions, respectively. Indeed, Figure 1c shows that for $\mathrm{Gn}-\mathrm{OH}$ there is a linear relationship between the number of complexed $\mathrm{Cu}^{2+}$ ions and the number of intradendrimer tertiary amine groups.

$\mathrm{Cu}^{2+}$ also binds to amine-terminated PAMAM dendrimers $\left(\mathrm{Gn}-\mathrm{NH}_{2}\right)$. Spectrophotometric titrations of these materials are consistent with the data for $\mathrm{G} 4-\mathrm{OH}$, but there is a more complex, $\mathrm{pH}$-dependent equilibrium (a consequence of the terminal primary amines) that is beyond the scope of this discussion. ${ }^{30}$

Intradendrimer Complexes between PAMAM Dendrimers and Metal Ions Other than $\mathrm{Cu}^{2+}$. In addition to $\mathrm{Cu}^{2+}$, many other transition-metal ions, including $\mathrm{Pd}^{2+}$, $\mathrm{Pt}^{2+}, \mathrm{Ni}^{2+}, \mathrm{Fe}^{3+}, \mathrm{Mn}^{2+}, \mathrm{Au}^{3+}$, and $\mathrm{Ru}^{3+}$, can be extracted into dendrimer interiors. ${ }^{4-6,30,33-36}$ For example, a strong absorption peak at $250 \mathrm{~nm}$ arising from a ligand-to-metal charge-transfer (LMCT) transition following purification by dialysis indicates that $\mathrm{PtCl}_{4}{ }^{2-}$ is sorbed within $\mathrm{Gn}-\mathrm{OH}$ 


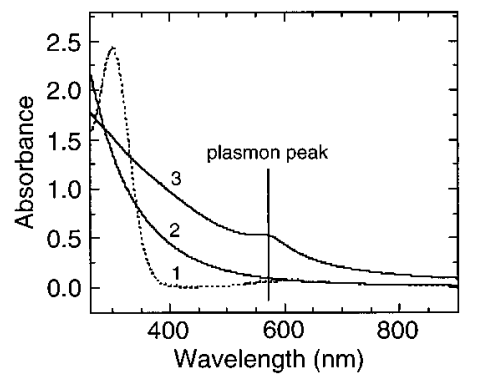

FIGURE 2. Absorption spectra of a solution containing $0.6 \mathrm{mM}$ $\mathrm{CuSO}_{4}$ and $0.05 \mathrm{mM} \mathrm{G} 4-\mathrm{OH}$ before (dashed line, spectrum 1) and after (solid line, spectrum 2) reduction with a 5 -fold molar excess of $\mathrm{NaBH}_{4}$. Spectrum 3 was obtained under the same conditions as

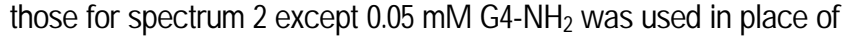
G4-OH.

dendrimers. The spectroscopic data also indicate that the nature of the interaction between the dendrimer and $\mathrm{PtCl}_{4}{ }^{2-}$ ions is quite different than for $\mathrm{Cu}^{2+}$. While $\mathrm{Cu}^{2+}$ interacts with tertiary amine groups by complexation, $\mathrm{PtCl}_{4}{ }^{2-}$ undergoes a slow ligand-exchange reaction involving substitution of one chloride ion for one interior tertiary amine. Importantly, the absorbance at $250 \mathrm{~nm}$ is proportional to the number of $\mathrm{Pt}^{2+}$ ions associated with the dendrimer over the range $0-60\left(\mathrm{G} 4-\mathrm{OH}\left(\mathrm{Pt}^{2+}\right)_{n}, \mathrm{n}=0-60\right)$, which indicates that it is possible to accurately control the average $\mathrm{Pt}^{2+} / \mathrm{G} 4-\mathrm{OH}$ ratio. ${ }^{5,30}$ Similar results have been obtained for $\mathrm{Pd}^{2+}$.

Direct Reduction of Dendrimer/Metal-Ion Composites. Chemical reduction of $\mathrm{Cu}^{2+}$-loaded G4-OH dendrimers $\left(\mathrm{G} 4-\mathrm{OH}\left(\mathrm{Cu}^{2+}\right)_{n}\right)$ with excess $\mathrm{NaBH}_{4}$ results in formation of intradendrimer $\mathrm{Cu}$ clusters (Scheme 1). Evidence for this comes from the immediate change in solution color from blue to golden brown; that is, the absorbance bands originally present at $\sim 605$ and $300 \mathrm{~nm}$ disappear and are replaced with a monotonically increasing spectrum of nearly exponential shape toward shorter wavelengths (Figure 2). These spectral changes result from the appearance of a new interband transition corresponding to formation of intradendrimer $\mathrm{Cu}$ clusters. The measured onset of this transition at $590 \mathrm{~nm}$ agrees with the reported value for Cu clusters, and the nearly exponential shape is characteristic of a bandlike electronic structure, strongly suggesting that the reduced $\mathrm{Cu}$ does not exist as isolated atoms, but rather as clusters. ${ }^{37}$ The absence of an absorption peak arising from Mie plasmon resonance (around $570 \mathrm{~nm}$ ) indicates that the $\mathrm{Cu}$ clusters are smaller than about $4 \mathrm{~nm} .38,39$ The presence of metal clusters is also supported by loss of signal in the EPR spectrum following reduction of the dendrimer/ $\mathrm{Cu}^{2+}$ composite.

Intradendrimer $\mathrm{Cu}$ clusters are extremely stable despite their small size, which provides additional strong evidence that the clusters reside within the dendrimer interior. Clusters formed in the presence of $\mathrm{G} 4-\mathrm{OH}$ or $\mathrm{G6}-\mathrm{OH}$ dendrimers and with a $\mathrm{Cu}^{2+}$ loading less than the maximum threshold values were found to be stable (no observable agglomeration or precipitation) for at least one week in an $\mathrm{O}_{2}$-free solution. However, in air-saturated solutions the clusters revert to intradendrimer $\mathrm{Cu}^{2+}$ ions overnight.

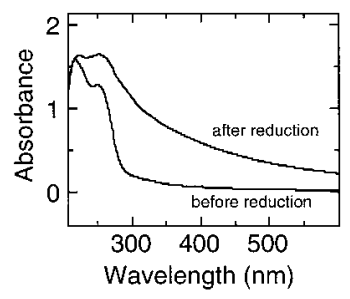

FIGURE 3. Absorption spectra of solutions containing $0.05 \mathrm{mM} \mathrm{G4-}$ $\mathrm{OH}\left(\mathrm{Pt}^{2+}\right)_{60}$ before and after reduction.

The ability to prepare well-defined intradendrimer metal nanoclusters depends on the chemical composition of the dendrimer. For example, when $\mathrm{G} 4-\mathrm{NH}_{2}$, rather than the just-described hydroxyl-terminated dendrimers, is used as the template, a maximum of $36 \mathrm{Cu}^{2+}$ ions are sorbed at $8<\mathrm{pH}<10$; most of these bind to the terminal primary amine groups. Reduction of a solution containing $0.6 \mathrm{mM} \mathrm{CuSO}_{4}$ and $0.05 \mathrm{mM} \mathrm{G}-\mathrm{NH}_{2}$ results in a clearly observable plasmon resonance band at $570 \mathrm{~nm}$ (spectrum 3, Figure 2), ${ }^{37,38}$ indicating that $\mathrm{Cu}$ clusters prepared in this way are larger than $4 \mathrm{~nm}$ in diameter. This increase in size is a consequence of agglomeration of Cu particles adsorbed to the unprotected dendrimer exterior.

The approach for preparing dendrimer-encapsulated Pt metal particles is similar to that used for $\mathrm{Cu}$ : chemical reduction of an aqueous solution of $\mathrm{G} 4-\mathrm{OH}\left(\mathrm{Pt}^{2+}\right)_{n}$ yields dendrimer-encapsulated Pt nanoparticles (G4-OH( $\left.\left(\mathrm{Pt}_{n}\right)\right)$. Spectra of $\mathrm{G} 4-\mathrm{OH}\left(\mathrm{Pt}^{2+}\right)_{60}$ before and after reduction are shown in Figure 3. After reduction, the absorbance is much higher throughout the wavelength range displayed. This change results from the interband transition of the encapsulated zerovalent Pt metal particles. Control experiments demonstrate that the Pt clusters are sequestered within the $\mathrm{G} 4-\mathrm{OH}$ dendrimers. For example, $\mathrm{BH}_{4}^{-}$reduction of $\mathrm{G} 4-\mathrm{NH}_{2}\left(\mathrm{Pt}^{2+}\right)_{n}$, which exists as a cross-linked emulsion, results in immediate precipitation of large $\mathrm{Pt}$ particles. In contrast, $\mathrm{Gn}-\mathrm{OH}$-encapsulated particles do not agglomerate for up to 150 days, and they redissolve in solvent after repeated solvation/drying cycles.

High-resolution transmission electron microscopy (HRTEM) images (Figure 4) clearly show that dendrimerencapsulated particles are nearly monodisperse and that their shape is roughly spherical. For $\mathrm{G} 4-\mathrm{OH}\left(\mathrm{Pt}_{40}\right)$ and G4$\mathrm{OH}\left(\mathrm{Pt}_{60}\right)$ particles, the metal particle diameters are $1.4 \pm$ 0.2 and $1.6 \pm 0.2 \mathrm{~nm}$, which are slightly larger than the theoretical values of 1.1 and $1.2 \mathrm{~nm}$, respectively, calculated by assuming that particles are contained within the smallest sphere circumscribing a fcc Pt crystal. X-ray energy dispersive spectroscopy (EDS) and X-ray photoelectron spectroscopy (XPS) analyses were also carried out, and they unambiguously identify the particle composition as zerovalent Pt. ${ }^{5}$ The XPS data also indicate a 3:1 ratio of $\mathrm{Cl}^{-} / \mathrm{Pt}^{2+}$ prior to reduction, providing additional support for the aforementioned ligand-exchange reaction, but $\mathrm{Cl}^{-}$ is not detectable after reduction. Results similar to those discussed for dendrimer-encapsulated $\mathrm{Cu}$ and $\mathrm{Pt}$ also obtain for $\mathrm{Pd}, \mathrm{Ru}$, and $\mathrm{Ni}$ nanoclusters. An example of $40-$ atom $\mathrm{Pd}$ nanoclusters confined within $\mathrm{G} 4-\mathrm{OH}$ is shown in the bottom micrograph of Figure 4. 


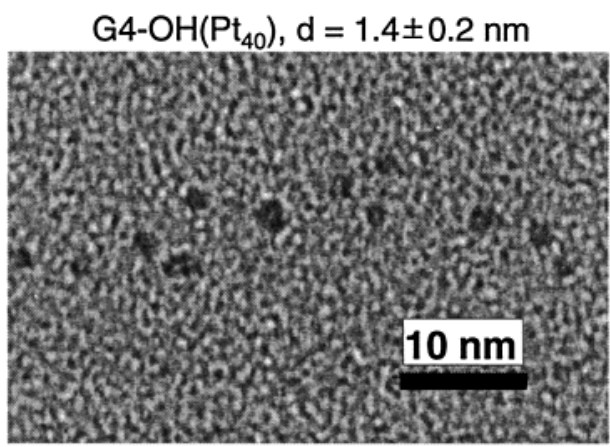

$\mathrm{G} 4-\mathrm{OH}\left(\mathrm{Pt}_{60}\right), \mathrm{d}=1.6 \pm 0.2 \mathrm{~nm}$

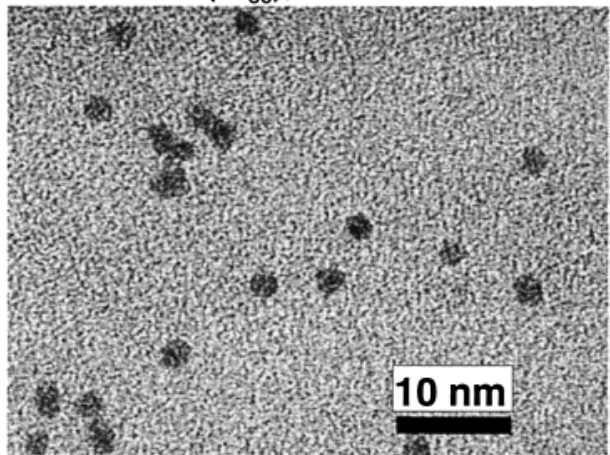

$\mathrm{G} 4-\mathrm{OH}\left(\mathrm{Pd}_{40}\right), \mathrm{d}=1.3 \pm 0.3 \mathrm{~nm}$

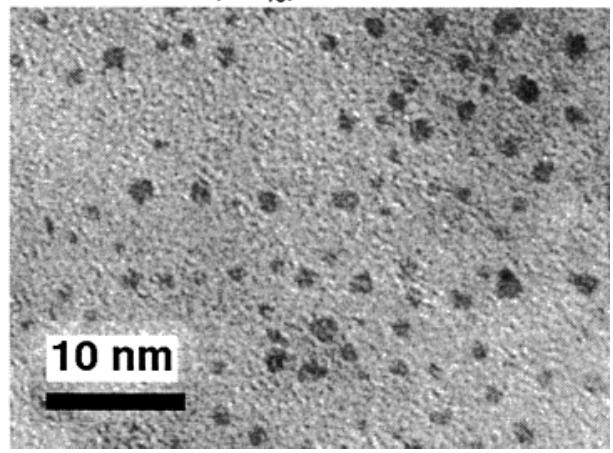

FIGURE 4. HRTEM images of G4-OH( $\left(\mathrm{Pt}_{40}\right), \mathrm{G} 4-\mathrm{OH}\left(\mathrm{Pt}_{60}\right)$, and $\mathrm{G} 4-\mathrm{OH}$ $\left(\mathrm{Pd}_{40}\right)$, which illustrate the size and shape distribution of the encapsulated metal nanoparticles.

Intradendrimer Metal-Displacement Reactions. In the previous section it was shown that dendrimer-encapsulated metal nanoclusters could be prepared by direct reduction if the corresponding metal ions could be extracted into the dendrimer interior. However, this approach is not suitable for encapsulation of nanoparticles whose precursor ions are not strongly complexed. Such is the case for $\mathrm{Ag}^{+}$.

Although it is not possible to prepare Ag particles inside $\mathrm{Gn}-\mathrm{OH}$ by direct reduction of interior ions, stable dendrimer-encapsulated Ag particles can be prepared by a metal displacement reaction. ${ }^{6}$ In this approach, dendrimer-encapsulated $\mathrm{Cu}$ nanoclusters are prepared as described earlier, ${ }^{3}$ and then upon exposure to $\mathrm{Ag}^{+}$the $\mathrm{Cu}$ particles oxidize to $\mathrm{Cu}^{2+}$ ions and $\mathrm{Ag}^{+}$is reduced to yield a dendrimer-encapsulated zerovalent Ag nanoparticle (Scheme 3 and eq 1).

$$
\mathrm{Cu}+2 \mathrm{Ag}^{+} \rightleftarrows \mathrm{Cu}^{2+}+2 \mathrm{Ag}
$$

Figure 5 shows the spectroscopic evolution of an

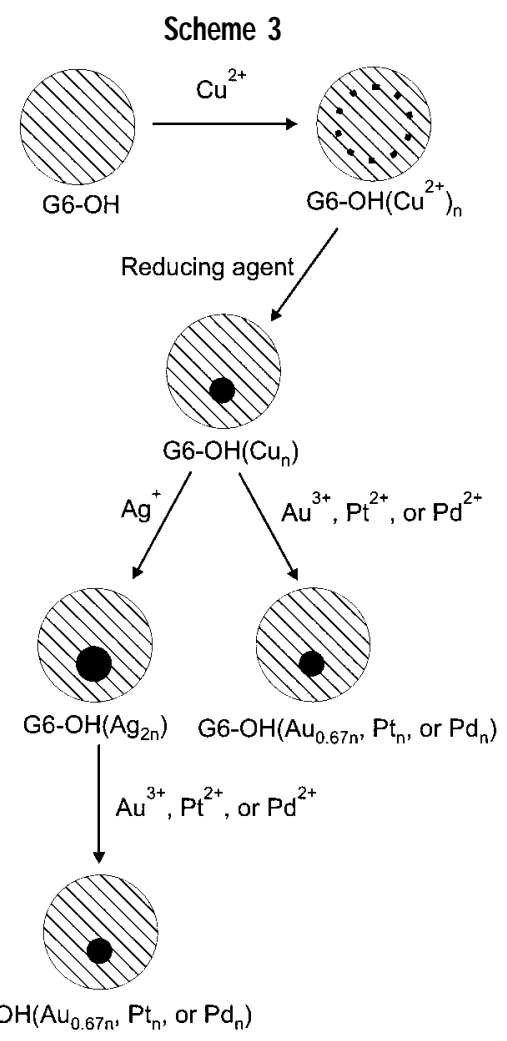

intradendrimer displacement reaction between $\mathrm{G} 6-\mathrm{OH}$ $\left(\mathrm{Cu}_{55}\right)$ and $\mathrm{Ag}^{+}$. Spectrum 1 is the UV-vis spectrum of G6$\mathrm{OH}\left(\mathrm{Cu}_{55}\right)$. When $\mathrm{Ag}^{+}$is added to this solution at $\mathrm{pH} 3.0$, a new absorbance band centered at $\sim 400 \mathrm{~nm}$ appears (spectrum 2), which corresponds to the plasmon resonance of Ag particles. ${ }^{37}$ When the $\mathrm{pH}$ of the solution is adjusted to 7.5 (spectrum 3), the Ag plasmon peak does not change much, but a new peak at $300 \mathrm{~nm}$ appears. This is the LMCT band for intradendrimer $\mathrm{Cu}^{2+}$ discussed earlier, and it indicates that at neutral $\mathrm{pH}$ both the metallic $\mathrm{Ag}$ nanoparticles and the $\mathrm{Cu}^{2+}$ ions generated by the displacement reaction are simultaneously present within the dendrimers. Such versatile and well-defined nanoenvironments provide a striking example of the value of retaining the template following nanoparticle formation. Composite materials such as these should find a variety of fundamental and applied applications, especially in the area of catalysis.

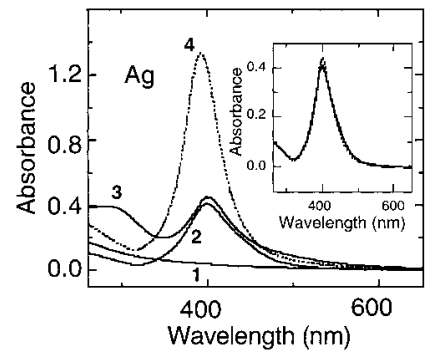

FIGURE 5. Absorption spectra resulting from intradendrimer displacement reactions. (1) $0.01 \mathrm{mM} \mathrm{G6-OH}\left(\mathrm{Cu}_{55}\right)$. (2) Same as spectrum 1 after addition of $1.1 \mathrm{mM} \mathrm{Ag}^{+}$at $\mathrm{pH}$ 3.0. (3) Same as spectrum 2, but at pH 7.5. The inset compares spectra obtained 10 min (solid line) and $18 \mathrm{~h}$ (dashed line) after the displacement reaction at $\mathrm{pH}$ 3. (4) Spectrum resulting from direct reduction of a solution containing $1.1 \mathrm{mM} \mathrm{Ag}+$ and $0.01 \mathrm{mM} \mathrm{G6-OH}$. 
Scheme 4

1. Partial Displacement reaction method
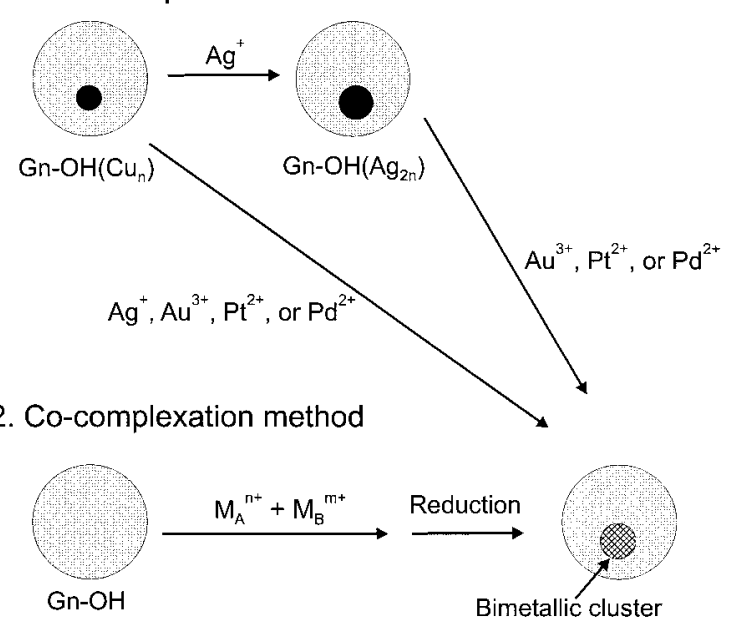

3. Sequential loading method

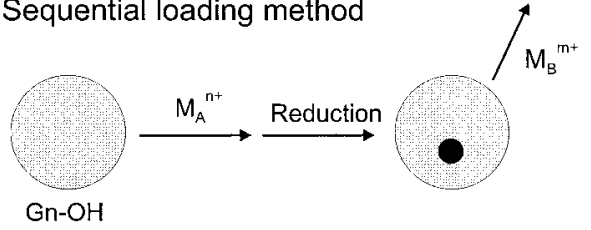

The Ag particles synthesized by this displacement reaction are very stable; for example, spectra taken $10 \mathrm{~min}$ and $18 \mathrm{~h}$ after reduction are nearly identical (Figure 5, inset), and no precipitation is observed even after storage in air for $>2$ months. XPS and TEM analyses confirm the presence of dendrimer-encapsulated Ag metal particles formed by displacement. This displacement method can be used to prepare other types of noble metal particles (Scheme 3), such as Au, Pt, and Pd, because the standard potentials $\left(\mathrm{E}^{\circ}\right)$ of the corresponding half-reactions are more positive than those for $\mathrm{Cu}^{2+} / \mathrm{Cu}$. Finally, Ag nanoparticles synthesized by primary displacement of dendrimer-encapsulated Cu nanoparticles can themselves be displaced to yield $\mathrm{Au}$, Pt, or Pd nanoparticles by secondary displacement reactions (Scheme 3).

Dendrimer-Encapsulated Bimetallic Nanoparticles. Bimetallic metal nanoparticles are important materials because they often display properties that are quite different from those of the individual metals. Such materials are particularly attractive for catalysis. Dendrimerencapsulated bimetallic nanoparticles can be synthesized by the three routes shown in Scheme 4 .

Preparation of mixed-metal intradendrimer nanoparticles by partial displacement is a straightforward extension of the total displacement approach for forming singlemetal nanoparticles described in the previous section. For example, if less than a stoichiometric amount of $\mathrm{Ag}^{+}, \mathrm{Au}^{3+}$, $\mathrm{Pd}^{2+}$, or $\mathrm{Pt}^{2+}$ is added to a $\mathrm{G} 6-\mathrm{OH}\left(\mathrm{Cu}_{n}\right)$ solution, it is possible to form dendrimer-encapsulated $\mathrm{Ag} / \mathrm{Cu}, \mathrm{Au} / \mathrm{Cu}$, $\mathrm{Pd} / \mathrm{Cu}$, or Pt/Cu bimetallic nanoparticles, respectively.

Dendrimer-encapsulated bimetallic nanoparticles can also be prepared by simultaneous co-complexation of two different metal ions, followed by a single reduction step.
For example, the absorption spectrum of a solution containing $\mathrm{G6}-\mathrm{OH}, \mathrm{PtCl}_{4}{ }^{2-}$, and $\mathrm{PdCl}_{4}{ }^{2-}$ is essentially the sum of the spectra of a solution containing $\mathrm{G} 6-\mathrm{OH}+$ $\mathrm{PtCl}_{4}{ }^{2-}$ and a second solution containing $\mathrm{G6}-\mathrm{OH}+$ $\mathrm{PdCl}_{4}{ }^{2-}$, which strongly suggests co-complexation of $\mathrm{Pt}^{2+}$ and $\mathrm{Pd}^{2+}$ within individual dendrimers. After reduction of these co-complexed materials, a new interband transition, which has an intensity different from that of either pure Pt or pure Pd nanoparticles, is observed.

The sequential loading method is also effective for preparing bimetallic nanoparticles. For example, dendrimer-encapsulated Pt/Pd nanoparticles are synthesized as follows. First, a solution containing $\mathrm{G6}-\mathrm{OH}\left(\mathrm{Pt}_{55}\right)$ is prepared by using the direct reduction approach already described. Next, $\mathrm{PdCl}_{4}{ }^{2-}$ is added to this solution to form a mixed metal-ion intradendrimer composite: $\mathrm{G} 6-\mathrm{OH}$ $\left[\left(\mathrm{Pt}_{55}\right)+\left(\mathrm{Pd}^{2+}\right)_{55}\right]$. That is, $\mathrm{Pd}^{2+}$ partitions into the dendrimer and complexes with tertiary amine sites vacated by $\mathrm{Pt}^{2+}$ after the first reduction step. The existence of the mixed-valent composite, which is nearly the sum of the two individual components, can be confirmed by UVvis spectroscopy. However, after reduction of G6-OH[( $\left(\mathrm{Pt}_{55}\right)$ $\left.+\left(\mathrm{Pd}^{2+}\right)_{55}\right]$, the intense LMCT band arising from $\mathrm{Pd}^{2+}$ complexed to interior tertiary amines essentially disappears, and the interband transition due to the formation of the bimetallic nanoparticles appears. TEM also indicates a significant increase in particle size following the second reduction step.

Presumably these three methods for preparing bimetallic, dendrimer-encapsulated nanoparticles can be extended to trimetallics, bi- and trimetallics having unique structures, and perhaps even core/shell materials. Thus far, however, we have not been able to conclusively prove the existence of the latter.

Homogeneous Catalysis Using Transition-Metal Nanoparticles. Transition-metal nanoparticles are important in the field of catalysis. ${ }^{40,41}$ As discussed earlier, catalytic nanoparticles are usually prepared by reduction of metal salts in the presence of stabilizers. The purpose of the stabilizers, which include polymers, ligands, and surfactants, is to control particle size and prevent agglomeration. However, stabilizers can also passivate nanoparticle surfaces. For some applications, including catalysis, it is desirable to prepare small, stable, but not-fully-passivated particles so that substrates can access the particle surface. Accordingly, two challenges that are important in this area of catalysis are (1) the development of methods for stabilizing nanoparticles by eliminating aggregation without blocking most of the active sites on the nanoparticle surfaces or otherwise reducing catalytic efficiency, and (2) controlling nanoparticle size, size distribution, and perhaps even particle shape. Because dendrimers can act as both "nanoreactors" for preparing nanoparticles and nanoporous stabilizers for preventing aggregation, we reasoned that they would be useful for addressing these two issues. As discussed below, dendrimer-encapsulated catalysts (DECs) do exhibit a number of intriguing properties.

Homogeneous Catalysis in Water Using Dendrimer- 


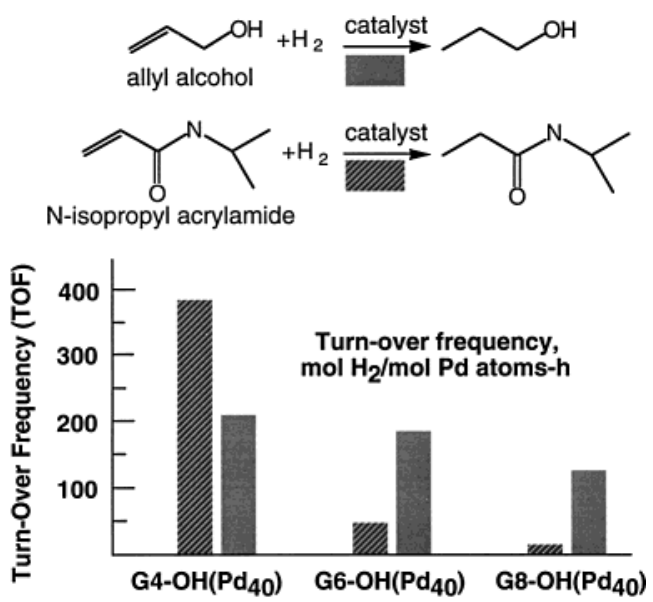

FIGURE 6. Turnover frequencies for hydrogenation of allyl alcohol and $\mathrm{N}$-isopropyl acrylamide obtained in water using dendrimerencapsulated Pd nanoparticles. The dendrimer generation varies but the average size of the $\mathrm{Pd}$ cluster is constant.

Encapsulated Metal Nanoparticles. Ligand- or polymerstabilized colloidal noble metals have been used for many years as catalysts for the hydrogenation of unsaturated organic molecules. ${ }^{42}$ Additionally, there is a special interest in developing "green" methodologies for catalyzing organic reactions in aqueous solutions. Accordingly, we investigated the homogeneous catalytic hydrogenation of alkenes in aqueous solutions using dendrimer-encapsulated nanoparticles. ${ }^{4}$ The hydrogenation activities for dendrimer-encapsulated Pd nanoparticles for a simple, unbranched alkene (allyl alcohol) and an electrondeficient, branched alkene ( $\mathrm{N}$-isopropyl acrylamide) in water are given in Figure 6. GC and NMR confirmed the presence of the saturated products. Similar data have been obtained for dendrimer-encapsulated Pt nanoparticles.

$\mathrm{G} 4-\mathrm{OH}\left(\mathrm{Pd}_{40}\right)$ efficiently catalyzes hydrogenation of both the linear and branched alkenes. For example, the turnover frequencies (TOFs, moles of $\mathrm{H}_{2}$ per mole of metal atoms per hour) for $\mathrm{G} 4-\mathrm{OH}\left(\mathrm{Pd}_{40}\right)$ for hydrogenation of $\mathrm{N}$-isopropyl acrylamide and for allyl alcohol hydrogenation compare favorably to those of water-soluble, polymerbound $\mathrm{Rh}(\mathrm{I})$ catalysts. ${ }^{42}$ The important result is that substrates (the alkenes and hydrogen in this case) can penetrate dendrimers, encounter the nanoparticle therein, and undergo intradendrimer chemical reactions.

Importantly, the hydrogenation reaction rate can be controlled by using dendrimers of different generations. This key finding is a consequence of generation-dependent dendrimer porosity: higher generation materials are more sterically crowded on their periphery and thus less porous and less likely to admit substrates to interior metal nanoparticles than those of lower generation. $4,11,12$ That is, the dendrimer acts as a selective nanoscopic filter that controls the catalytic activity of the composite. For example, the TOFs for $\mathrm{G} 6-\mathrm{OH}\left(\mathrm{Pd}_{40}\right)$ and $\mathrm{G} 8-\mathrm{OH}\left(\mathrm{Pd}_{40}\right)$ are only $10 \%$ and $5 \%$, respectively, of that of $\mathrm{G} 4-\mathrm{OH}\left(\mathrm{Pd}_{40}\right)$ for $\mathrm{N}$-isopropyl acrylamide. However, when the same materials are used to reduce the linear alkene, a much smaller decrease in activity is noted. This result shows that it is possible to control reaction rates and do selective catalysis
Scheme 5

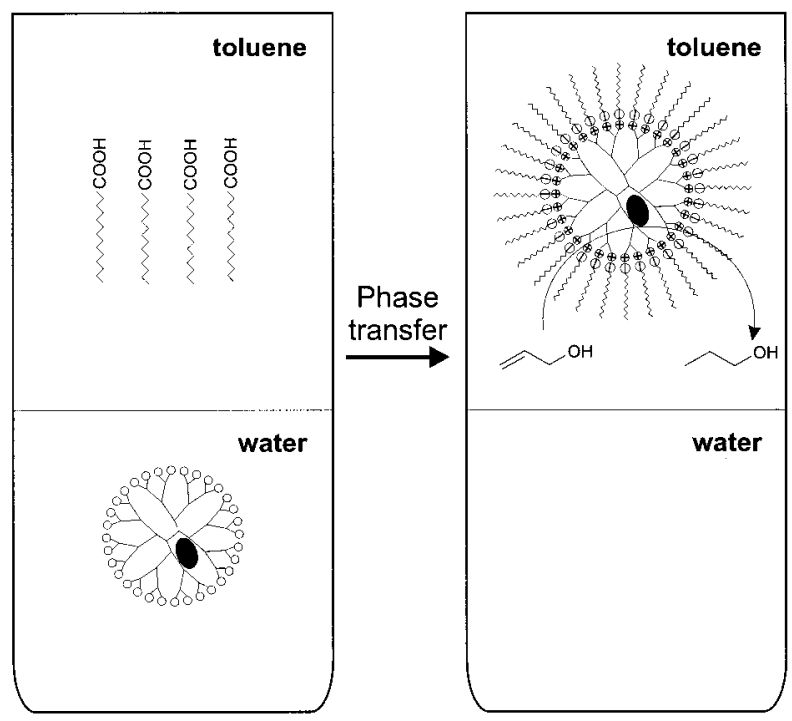

by adjusting the "mesh" of the dendrimer "nanofilter". In this case, the high-generation dendrimers selectively excluded the branched alkene, but the linear molecule was able to pass through the dense G6 and G8 exteriors and encounter the catalyst. These findings represent an excellent example of how a template (the dendrimer) can be used to add functionality to a nanoparticle: by retaining the template following casting of the nanoparticle, a significant new property (gating) obtains.,11

Homogeneous Catalysis in Organic Solvents Using Dendrimer-Encapsulated Metal Nanoparticles. We also tested dendrimer-encapsulated Pd nanoparticles for their hydrogenation activity in organic phases. As mentioned previously, the solubility of dendrimers can be controlled by functionalization of the terminal groups. For example, alkyl functionalization renders the otherwise hydrophilic PAMAM dendrimers soluble in toluene. Importantly, functional groups need not be added to the dendrimer by covalent grafting, although this is certainly a viable strategy. A simpler and more versatile approach that is suitable for many applications takes advantage of the acid-base interaction between fatty acids and dendrimer terminal amine groups. ${ }^{8}$

We were able to demonstrate this strategy as follows. First, Pd nanoparticles were prepared within amineterminated PAMAM dendrimers. To prevent coordination of $\mathrm{Pd}^{2+}$ to the primary amine groups of the dendrimers, which induces cross-linking and precipitation, the solution $\mathrm{pH}$ was adjusted to $\sim 2$, which preferentially protonates the exterior amines to a greater extent than the interior tertiary amines. Accordingly, $\mathrm{Pd}^{2+}$ binds preferentially to the interior. Upon chemical reduction, Pd particles form only within the dendrimer interior. $\mathrm{G} 4-\mathrm{NH}_{2}$-encapsulated nanoparticles can then be quantitatively transported from an aqueous phase into toluene by addition of $10-20 \%$ of dodecanoic acid to the organic phase (Scheme 5). ${ }^{8}$ This transition is readily visualized by the color change: the brown aqueous solution of $\mathrm{Pd}$ nanoparticles becomes clear after addition of the acid, while the toluene layer turns brown. Our studies have shown that this is a 


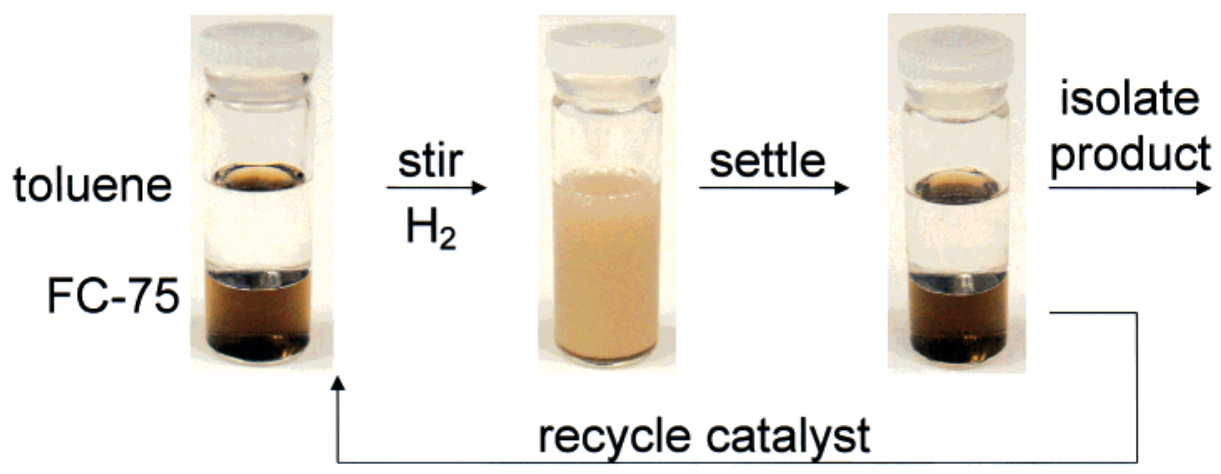

FIGURE 7. Illustration of the approach used to carry out fluorous biphasic catalysis using dendrimer-encapsulated metal nanoparticles

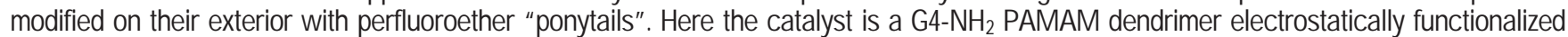
with a perfluoroether fatty acid using a strategy similar to that shown in Scheme 5.

consequence of the formation of monodisperse, inverted micelles templated by the dendrimer (Scheme 5). Remarkably, these interesting hybrid materials have catalytic activities for hydrogenation exceeding those observed for the same reactions run in aqueous solutions. This may be a consequence of the relatively hydrophilic nature of the dendrimer compared to the solvent; that is, mass transfer of the substrate may be facilitated by the difference in polarity of the dendrimer interior relative to the solvent.

Homogeneous Catalysis in Fluorous/Organic Biphasic Solvents Using Dendrimer-Encapsulated Metal Nanoparticles. Reactions in biphasic fluorous/ organic solvents were suggested by Horváth and Raba in $1994^{43}$ to facilitate recovery and recycling of soluble catalysts. Such systems consist of organic and fluorous layers: the catalyst is designed to be selectively soluble in the fluorous phase, while the reactants are preferentially soluble in the organic solvent. Stirring or heating of the mixture leads to formation of a fine emulsion, and the catalytic reaction proceeds at the interface between the two liquids. When the reaction is complete, the phases are allowed to settle, the product is isolated from the organic phase, and the catalyst-containing fluorous layer is recycled as shown in Figure 7.

We recently described two new approaches for using dendrimer-encapsulated metal particles to perform biphasic catalysis. The first is hydrogenation catalysis using PAMAM dendrimers rendered soluble in the fluorous phase by electrostatic attachment of perfluoroether groups. ${ }^{9}$ The second illustrates the use of perfluoroether groups covalently linked to the exterior of PPI dendrimers to carry out a carbon-coupling Heck reaction. ${ }^{7}$ In both cases the fluorous-soluble, dendrimer-based catalyst was recyclable. Moreover, the reactions resulted in selectivities and products that might reflect the unique nanoenvironment of the reaction volume defined by the dendrimer interior.

For example, the Heck reaction between iodobenzene and n-butyl acrylate resulted in 100\% selectivity of $n$-butyl trans-formylcinnamate, whereas in the absence of the dendrimer the selectivity is $74-98 \%$. Our studies have not progressed far enough to allow us to draw correlations between dendrimer structure and intradendrimer reactivity, but this will obviously be a fruitful avenue for additional study. Interestingly, the temperature at which the reaction proceeds is also somewhat lower than that in both the classic Heck reaction conditions ${ }^{44}$ and those used for stabilized colloidal Pd particles $\left(90^{\circ} \mathrm{C}\right.$ vs $>120$ ${ }^{\circ} \mathrm{C}$ and $130^{\circ} \mathrm{C}$, respectively). ${ }^{45}$ Depending on the reactants and conditions, the unoptimized yields range between 35 and $85 \%$. Importantly, the success of this Heck reaction conclusively proves that it is possible to catalyze synthetically useful carbon-carbon bond-forming reactions between two fairly large reactants within a dendrimer interior.

Homogeneous Catalysis in Supercritical $\mathrm{CO}_{2}$ Using Dendrimer-Encapsulated Metal Particles. As mentioned earlier, there are good reasons to search for reaction conditions that eliminate the need for organic solvents. The use of liquid or supercritical $\mathrm{CO}_{2}\left(\mathrm{scCO}_{2}\right)$ addresses the issues of catalyst recovery, toxicity, and product recovery. ${ }^{46} \mathrm{Until}$ recently, however, the use of $\mathrm{scCO}_{2}$ had been limited to organometallic Pd complexes functionalized with perfluorinated ligands, ${ }^{47-49}$ due to the limited solubility of metal colloids in $\mathrm{CO}_{2}$, and often required the use of water as a cosolvent. ${ }^{50}$ The work described here shows that dendrimers can be used to solubilize $\mathrm{Pd}$ nanoparticles in liquid and $\mathrm{sCCO}_{2}$, and that this catalytic system promotes Heck chemistry.

As discussed earlier, perfluorinated polyether "ponytails" can be covalently grafted onto dendrimers, and DeSimone et al. showed that such materials are soluble in liquid $\mathrm{CO}_{2} .{ }^{51}$ Preliminary results from a study of catalytic activation of the heterocoupling between aryl halides and alkenes using ponytail-functionalized dendrimer-encapsulated Pd nanoparticles have been promising. For example, the classic Pd-catalyzed Heck coupling between aryl halides and methacrylate yields predominately (>97\%) the trans-cinnimaldehyde product. ${ }^{52}$ On the other hand, the $\mathrm{CO}_{2}$-soluble dendrimer nanocomposite exclusively catalyzes the production of the highly unfavored 2-phenylacrylic acid methyl ester isomer at $5000 \mathrm{psi}$ and $75^{\circ} \mathrm{C} .{ }^{10}$

\section{Summary, Conclusions, and Outlook}

This Account has described composite materials we call dendrimer-encapsulated nanoparticles. We first reported these interesting inorganic/organic hybrid materials in 
$1998,{ }^{3}$ and within several months the results were confirmed by others. ${ }^{53} \mathrm{M}$ ore recently, Amis and co-workers, ${ }^{35}$ Esumi et al., ${ }^{36}$ and Goodson ${ }^{54}$ have provided remarkably detailed microscopy, scattering, and photophysical data that have yielded additional insight into dendrimer encapsulation of metal nanoparticles. New results from our laboratory indicate that even semiconductor quantum dots (CdS) are accessible by this synthetic route, ${ }^{55}$ and Amis et al. have further expanded the scope of dendrimer-encapsulated nanoparticles by preparing them within monolithic dendrimer-containing polymer composites. ${ }^{29,34}$

The approach described here for preparing dendrimerencapsulated nanoparticles takes advantage of the unique aspects of dendrimer structure: the chemistry of the terminal groups, the generation-dependent size, the threedimensional structure, the radial distribution function of polymer density, and the presence of endoreceptors within the dendrimer interior.

The preparation of dendrimer-encapsulated nanoparticles is generally rather simple. For example, the dendrimers used in this study are all commercially available, end-group modifications normally involve a single synthetic step, and separations are generally straightforward. Such simplicity should be a strong enticement to workers in the fields of catalysis, biotechnology, medicine, electronics, photonics, physics, materials science, and engineering to (1) begin to use the types of materials described herein for technological applications and fundamental discoveries, (2) invent new, related materials, and (3) integrate these dendrimer composites into the next generation of molecular machines and devices.

Weacknowledge our co-workers past and present who contributed to the results described in this Account. We are especially grateful to Prof. Daniel Romo (Texas A\&M) who suggested Heck chemistry as a good starting point to demonstrate intradendrimer carbon coupling reactions. Prof. Keith P. Johnston and C. Ted Lee, Jr. (The University of Texas, Austin), worked with us on the catalysis experiments in $\mathrm{CO}_{2}$. Mr. Mark Kaiser (then of Dendritech, Inc., but presently with Dow Corning, Auburn, MI), with whom wehave had the pleasure of collaborating for many years, provided invaluable technical advice and most of the PAMAM dendrimers used in our studies. We thank Dr. Eric Amis (NIST) for sharing his unpublished work with us. We are also grateful to the Office of Naval Research, the National Science Foundation, and the Robert A. Welch Foundation for providing financial support of this work. Additional support was provided via subcontract from Sandia National laboratories, which is supported by the U.S. Department of Energy (Contract DE-AC04-94AL8500). Sandia is a multiprogram laboratory operated by the Sandia Corporation, a Lockheed-Martin company, for the U.S. Department of Energy. M.Z. acknowledges fellowship support from The Electrochemical Society, Inc., the Eastman Chemical Company, and Phillips Petroleum. We are also indebted to Ms. Mary Sacquety for her careful and diligent editing of this manuscript.

\section{References}

(1) Buhleier, E.; Wehner, W.; Vogtle, F. "Cascade" and "NonskidChain-Like" Synthesis of Molecular Cavity Topologies. Synthesis 1978, 155-158.
(2) Bosman, A. W.; J anssen, H. M.; Meijer, E. W. About Dendrimers: Structure, Physical Properties, and Applications. Chem. Rev. 1999, 99, 1665-1688.

(3) Zhao, M.; Sun, L.; Crooks, R. M. Preparation of Cu Nanoclusters within Dendrimer Templates. J . Am. Chem. Soc. 1998, 120, 48774878.

(4) Zhao, M.; Crooks, R. M. Homogeneous Hydrogenation Catalysis using Monodisperse, Dendrimer-Encapsulated Pd and Pt Nanoparticles. Angew. Chem., Int. Ed. 1999, 38, 364-366.

(5) Zhao, M.; Crooks, R. M. Dendrimer-Encapsulated Pt Nanoparticles: Synthesis, Characterization, and Applications to Catalysis. Adv. Mater. 1999, 11, 217-220.

(6) Zhao, M.; Crooks, R. M. Intradendrimer Exchange of Metal Nanoparticles. Chem. Mater. 1999, 11, 3379-3385.

(7) Yeung, L. K.; Crooks, R. M. Heck Heterocoupling within a Dendritic Nanoreactor. Nano Lett. 2001, in press.

(8) Chechik, V: Zhao, M.; Crooks, R. M. Self-Assembled Inverted Micelles Prepared from a Dendrimer Template: Phase Transfer of Encapsulated Guests. J . Am. Chem. Soc. 1999, 121, 4910-4911.

(9) Chechik, V.; Crooks, R. M. Dendrimer-Encapsulated Pd Nanoparticles as Fluorous-Phase-Soluble Catalysts. J . Am. Chem. Soc. 2000, 122, 1243-1244.

(10) Yeung, L. K.; Lee, C. T., J r.; J ohnston, K. P.; Crooks, R. M. Heck Catalysis in Supercritical $\mathrm{CO}_{2}$ using Palladium Nanoparticles Encapsulated in Dendrimer Nanoreactors. J. Am. Chem. Soc. 2000, submitted.

(11) Zhao, M.; Tokuhisa, H.; Crooks, R. M. Interactions Between Organized, Surface-Confined Monolayers and Liquid-Phase Probe Molecules. 5. Molecule-Sized Gates Based on Surface-Confined Dendrimers. Angew. Chem., Int. Ed. Engl. 1997, 36, 2596-2598.

(12) Wells, M.; Crooks, R. M. Interactions between Organized, SurfaceConfined Monolayers and Vapor-Phase Probe Molecules. 10 Preparation and Properties of Chemically Sensitive Dendrimer Surfaces. J . Am. Chem. Soc. 1996, 118, 3988-3989.

(13) Tokuhisa, H.; Zhao, M.; Baker, L. A.; Phan, V. T.; Dermody, D. L.; Garcia, M. E.; Peez, R. F.; Crooks, R. M.; Mayer, T. M. Preparation and Characterization of Dendrimer Monolayers and DendrimerAlkylthiol Mixed Monolayers Adsorbed to Gold. J . Am. Chem. Soc. 1998, 120, 4492-4501.

(14) Tokuhisa, H.; Crooks, R. M. Interactions between Organized, Surface-Confined Monolayers and Vapor-Phase Probe Molecules. 12. Two New Methods for Surface-Immobilization and Functionalization of Chemically Sensitive Dendrimer Surfaces. Langmuir 1997, 13, 5608-5612.

(15) Hierlemann, A.; Campbell, J . K.; Baker, L. A.; Crooks, R. M.; Ricco, A. J. Structural Distortion of Dendrimers on Gold Surfaces: A Tapping-Mode AFM Investigation. J . Am. Chem. Soc. 1998, 120, 5323-5324.

(16) Forster, S.; Antonietti, M. Amphiphilic Block Copolymers in Structure-Controlled Nanomaterial Hybrids. Adv. Mater. 1998, 10, 195-217

(17) Schmid, G. Cluster and Colloids. From Theory to Applications; VCH: New York, 1994.

(18) Brust, M.; Walker, M.; Bethell, D.; Schiffrin, D. J .; Whyman, R. Synthesis of Thiol-Derivatized Gold Nanoparticles in a 2-Phase Liquid-Liquid System. J. Chem. Soc., Chem. Commun. 1994, 801-802.

(19) Hostetler, M.J .; Wingate, J . E.; Zhong, C.-J .; Harris, J . E.; Vachet, R. W.; Clark, M. R.; Londono, J. D.; Green, S. J .; Stokes, J . J .; Wignall, G. D.; Glish, G. L.; Porter, M. D.; Evans, N. D.; Murray, R. W. Alkanethiolate Gold Cluster Molecules with Core Diameters from 1.5 to $5.2 \mathrm{~nm}$ : Core and Monolayer Properties as a Function of Core Size. Langmuir 1998, 14, 17-30.

(20) Martin, C. R.; Mitchell, D. T. In Electroanalytical Chemistry; Bard, A. J ., Rubinstein, I., Eds.; Dekker: New York, 1999; Vol. 21, pp $1-74$.

(21) Schonenberger, C.; van der Zande, B. M. I.; Fokkink, L. G. I : Henny, M.; Schmid, C.; Kruger, M.; Bachtold, A.; Huber, R.; Birk, H.; Staufer, U. Template Synthesis of Nanowires in Porous Polycarbonate Membranes: Electrochemistry and Morphology. J . Phys. Chem. B 1997, 101, 5497-5505.

(22) Shelimov, K. B.; Moskovits, M. Composite Nanostructures Based on Template-Grown Boron Nitride Nanotubules. Chem. Mater. 1999, 12, 250-254.

(23) Hanus, L. H.; Sooklal, K.; Murphy, C. J .; Ploehn, H. J . Aggregation Kinetics of Dendrimer-Stabilized CdS Nanoclusters. Langmuir 2000, 16, 2621-2626.

(24) Garcia, M. E.; Baker, L. A.; Crooks, R. M. Preparation and Characterization of Dendrimer-Gold Colloid Nanocomposites. Anal. Chem. 1999, 71, 256-258.

(25) Esumi, K.; Suzuki, A.; Aihara, N.; Usui, K.; Torigoe, K. Preparation of Gold Colloids with UV Irradiation Using Dendrimers as Stabilizer. Langmuir 1998, 14, 3157-3159. 
(26) Esumi, K.; Suzuki, A.; Yamahira, A.; Torigoe, K. Role of Poly(amidoamine) Dendrimers for Preparing Nanoparticles of Gold, Platinum, and Silver. Langmuir 2000, 16, 2604-2608.

(27) Technical data from DSM Fine Chemicals (The Netherlands) and Dendritech, Inc. (Midland, MI).

(28) J ansen, J . F. G. A.; de Brabander-van den Berg, E. M. M.; Meijer, E. W. Encapsulation of Guest Molecules into a Dendritic Box. Science 1994, 266, 1226-1229.

(29) Zhao, M.; Liu, Y.; Crooks, R. M.; Bergbreiter, D. E. Preparation of Highly Impermeable Hyperbranched-Polymer Thin Film Coatings Using Dendrimers First as Building Blocks and then as In-situ Thermosetting Agents. J. Am. Chem. Soc. 1999, 121, 923-930.

(30) Crooks, R. M.; Lemon, B. I.; Yeung, L. K.; Zhao, M. DendrimerEncapsulated Metals and Semiconductors: Synthesis, Characterization, and Applications. Top. Curr. Chem. 2000, 212, 81-135.

(31) Ottaviani, M. F.; Bossmann, S.; Turro, N. J .; Tomalia, D. A. Characterization of Starburst Dendrimers by the EPR Technique. 1. Copper Complexes in Water Solution. J . Am. Chem. Soc. 1994, $116,661-671$.

(32) Because protons compete for the tertiary amine binding sites, the maximum number of $\mathrm{Cu}^{2+}$ ions that bind depends on $\mathrm{pH}$. At $\mathrm{pH}<3$ no binding is observed.

(33) Ottaviani, M. F.; Montalti, F.; Romanelli, M.; Turro, N.J .; Tomalia, D. A. Characterization of Starburst Dendrimers by EPR. 4. $\mathrm{Mn}$ (II) as a Probe of Interphase Properties. J. Phys. Chem. 1996, 100, 11033-11042.

(34) Grohn, F.; Kim, G.; Bauer, B. J .; Amis, E. J N Nanoparticle Formation within Dendrimer-Containing Polymer Networks: Route to New Organic-Inorganinc Hybrid Materials. Macromolecules, submitted.

(35) Grohn, F.; Bauer, B. J .; Akpalu, Y. A.; J ackson, C. L.; Amis, E. J. Dendrimer Templates for the Formaiton of Gold Nanoclusters. Macromolecules 2000, 33, 6042-6050.

(36) Esumi, K.; Nakamura, R.; Suzuki, A.; Torigoe, K. Preparation of Platinum Nanoparticles in Ethyl Acetate in the Presence of Poly(amidoamine) dendrimers with a Methyl Ester Terminal Group. Langmuir 2000, 16, 7842-7846.

(37) Kreibig, U.; Vollmer, M. Optical Properties of Metal Clusters; Springer: Berlin, 1995.

(38) Curtis, A. C.; Duff, D. G.; Edwards, P. P.; J efferson, D. A.; J ohnson, B. F. G.; Kirkland, A. I.; Wallace, A. S. A. A Morphology-Selective Copper Organosol. Angew. Chem., Int. Ed. Engl. 1988, 27, 15301533.

(39) Lisiecki, I.; Pileni, M. P. Synthesis of Copper Metallic Clusters Using Reverse Micelles as Microreactors. J . Am. Chem. Soc. 1993 115, 3887-3896.

(40) Lewis, L. N. Chemical Catalysis by Colloids and Clusters. Chem. Rev. 1993, 93, 2693-2730.
(41) Bradley, J. S. Clusters and Colloids; VCH: Weinheim, 1994.

(42) Bergbreiter, D. E.; Liu, Y.-S. Water-soluble Polymer-bound, Recoverable Palladium(0)-Phosphine Catalysts. Tetrahedron Lett. 1997, 38, 7843-7846.

(43) Horvath, I. T.; Raba, J . Facile Catalyst Separation Without Water: Fluorous Biphasic Hydroformylation of Olefins. Science 1994, 266, $72-75$.

(44) Heck, R. F. Palladium-Catalyzed Vinylation of Organic Halides. Org. React. 1982, 27, 345-390.

(45) Recently, however, Heck coupling was achieved at only $80^{\circ} \mathrm{C}$ in a biphasic solvent system using perfluorinated $\mathrm{Pd}$ coordination complexes. See: Moineau, J.; Pozzi, G.; Quici, S.; Sirou, D. Palladium-Catalyzed Heck Reaction in Perfluorinated Solvents. Tetrahedron Lett. 1999, 40, 7683-7686.

(46) Kaupp, G. Reactions in Supercritical Carbon-Dioxide. Angew. Chem., Int. Ed. Engl. 1994, 33, 1452-1455.

(47) Morita, D. K.; Pesiri, D. R.; David, S. A.; Glaze, W. H.; Tumas, W. Palladium-Catalyzed Cross-Coupling Reactions in Supercritical Carbon Dioxide. Chem. Commun. 1998, 13, 1397-1398.

(48) Carroll, M. A.; Holmes, A. B. Palladium-Catalyzed Cross-Coupling Reactions in Supercritical Carbon Dioxide. Chem. Commun. 1998, 13, 1395-1396.

(49) Bhanage, B. M.; Ikushima, Y.; Shirai, M.; Arai, M. Heck Reactions Using Water-Soluble Metal Complexes in Supercritical Carbon Dioxide. Tetrahedron Lett. 1999, 40, 6427-6430.

(50) Ji, M.; Chen, X. Y.; Wai, C. M.; Fulton, J . L. Synthesizing and Dispersing Silver Nanoparticles in a Water-in Supercritical Carbon Dioxide Microemulsion. J. Am. Chem. Soc. 1999, 121, 2631-2632.

(51) Cooper, A. I.; Londono, J . D.; Wignall, G.; McClain, J . B.; Samulski, E. T.; Lin, J. S.; Dobrynin, A.; Rubinstein, M.; Burke, A. L. C. Frechet, J. M. J .; DeSimone, J . M. Extraction of a Hydrophilic Compound from Water into Liquid $\mathrm{CO}_{2}$ using Dendritic Surfactants. Nature 1997, 389, 368-371.

(52) Heck, R. F.; Nolley, J . P. Palladium-Catalyzed Vinylic Hydrogen Substitution Reactions with Aryl, Benzyl, and Styryl Halides. J Org. Chem. 1972, 37, 2320-2322.

(53) Balogh, L.; Tomalia, D. A. Poly(Amidoamine) Dendrimer-Templated Nanocomposites. 1. Synthesis of Zerovalent Copper Nanoclusters. J. Am. Chem. Soc. 1998, 120, 7355-7356.

(54) Goodson, T. J., III., private communication.

(55) Lemon, B. I., III; Crooks, R. M. Preparation and Characterization of Dendrimer-Encapsulated CdS Semiconductor Quantum Dots. J. Am. Chem. Soc. 2000, 122, 12886-12887.

AR000110A 